[Zepke, N. (2008). Evidence-based Educational Policy Research: Some Questions. New Zealand Annual Review of Education, 17, 25-39]

\section{Evidence-based Educational Policy Research: Some Questions}

\author{
NICK ZEPKE
}

\section{Abstract:}

Hotly contested debates about evidence-based educational research, policy development and practice have become a feature of the educational landscape in New Zealand as elsewhere. Advocates argue that applying scientifically established research evidence of what works is the way to improve educational quality and student outcomes. Governments in the United States, United Kingdom and New Zealand support the development of scientific evidence-based policy and practice that shows what works. Doubters are not questioning the importance of scientific research evidence. Indeed it seems untenable to deny the centrality of evidence in decision-making about what works in education. Rather, sceptics and opponents question meanings of key terms like "science", "evidence" and "quality". They question the politics behind evidence-based research, assumptions about the nature of evidence, science and research methodology and whether research that aims to provide universal answers actually works. This article canvasses these questions. Written from a sceptical perspective, it draws on experiences from the United States, the United Kingdom and New Zealand.

A number of authors have noted the almost spontaneous emergence of similar educational policy discourses in developed countries (Ball, 1998; Daun, 2002). Edwards and Usher (2000) use the term "policy migration" to describe the process that enables comparable policies to be accepted in diverse jurisdictions. One policy discourse that has migrated widely holds that education is central to social and economic development in modernising societies. Knowledge and skills are key sources of competitive advantage in the global market place. Education becomes both the provider of the knowledge and skills required and a marketable service (Codd, 2002). Certainly, policy
26 Nick Zepke

imperatives and initiatives in countries such as the USA, UK and New Zealand emphasise the importance of education's role in developing a knowledge economy.

One aspect of this policy discourse is that educational policy is best when it is founded on sound research-based evidence of what works. In the United States, for example, the No Child Left Behind Act (2001, cited in Feuer, 2006) requires that institutions receiving federal grants use their funds on implementing evidence-based strategies (Adams St Pierre, 2006). In the United Kingdom, New Labour used the slogan "education, education, education" to place education at the centre of its modernising agenda (Mulderrig, 2003). Of seven characteristics listed as leading to modernisation, one states that policy should be based on all available best evidence (Davies \& Nutley, 2003). In New Zealand too, evidence-based policy has been given an important place in government thinking. Successive Statements of Intent (2003-2008, and 2005-2010) include goals to "promote evidence-based decision-making" (Ministry of Education, 2004, p. 16). The Ministry also followed the USA and the UK in stipulating that educational policy "must be informed, and respond to information about what works" (Ministry of Education, 2005, p. 13).

There is no question that it is desirable for research evidence to inform, even underpin, policy-making. However, questions do emerge about what kind of evidence shows what works. In the USA acceptable evidence is provided by quantitative scientific research, preferably randomised control experiments (Feuer, Towne \& Shavelson, 2002). In the UK there is also an emphasis on quantitative scientific research. Here this often takes the form of systematic review syntheses of multiple quantitative studies that demonstrate effect sizes of interventions (Boaz \& Pawson, 2005). New Zealand has not been as clear in expressing its preference for quantitative research. However, the Ministry's iterative Best Evidence Synthesis (BES) research programme, while recognizing the importance of context and, with a realist epistemology able to use non-quantitative research to supplement the quantitative, nevertheless looks to establish effect sizes of what works with trend data being given prominence (Alton-Lee, 2004, 2006). This article asks three questions about the growing dominance of scientific quantitative research in policy-making: why is there a tilt towards the quantitative scientific? Is this tilt justified? and, based on the assumption that evidence-based policy in education is desirable, what is the future of such policy? 


\section{Why is There A Tilt Towards the Quantitative Scientific?}

\section{Epistemological considerations}

I want to consider two answers. The first is rooted in epistemological issues. According to Hodkinson and Smith (2004), quantitative scientific research was the dominant paradigm from the enlightenment until the last 30 years of the previous century. This dominance rested on what Olson (2004) called the triumph of hope: that rigorous, objective scientific research, value-free, can get closer to the truth than any other kind of research. While always provisional, the hope was that the results of such research could separate what is real and what is subjectively believed. It enables variables to be identified and isolated. In isolating a variable, its effects could be recognized, and with inferential statistics, generalizations could be made (Feuer, 2006). Hodkinson and Smith (2004) suggest that this form of research has come under increasing attack. Notions of objectivity and the separation of the research subject from the researcher have been questioned. The complexity of social life and its contextual nature also leads to questioning. Increasingly, researchers found social life to be inexplicable when only considering the effects of isolating and researching separate variables (Howe, 2004).

This recognition that social life is complex and influenced by context has led to challenges to the quantitative scientific research paradigm by what Hodkinson and Smith (2004) call "the interpretive turn". The challenge has been marshalled under many banners - post-empiricism, transcendental realism, critical realism, constructivism, hermeneutics, pragmatism, fallibilism, critical theory and post-modernism are a few examples. While major differences exist between those that march under these banners, such as about whether reality can be known as it really is, a number of ideas are common to the banner carriers (Hodkinson \& Smith, 2004). These include that research is theory-driven and not values-free; that understanding the complexity of social life requires research that fosters deep theory-informed understandings of phenomena that can be used to construct and make meaning; and, following Sanderson (2003), that a pragmatic mixed-methods approach that includes qualitative research will best serve policy-makers to find out what works, for whom and in what circumstances. According to Adams St Pierre (2006), paradigm wars between the scientific and interpretative turns have simmered over the last 30 years with qualitative research producing the greater volume and variety of work but quantitative scientific research remaining the gold standard (Barone, 2007).

\section{Political considerations}

Until the 1990s, these paradigm wars were relatively unimportant to governments and policy makers. While they did not necessarily ignore research evidence, it played no specific role in policy-making (Taylor, 2005). The neo-liberal revolution that swept western countries during the 1980s changed this indifference. Neo-liberalism led to a much more dispersed state (Taylor, 2005) in which the market place competed with governments for policy direction. The state came to focus on new techniques of governance that would honour the role of the market while enabling governments to implement their policies at a distance. A specific meaning of accountability became one of the anchoring policy drivers for the dispersed neo-liberal state. Charlton (2002) sees accountability as having two relatively distinct meanings, one general and the other technical. It can refer to the general (mutual) responsibility that people have for each other, or it can apply to performances that can be audited. Biesta (2004) suggests that the latter meaning has been adopted by the dispersed neo-liberal state. He argues that an "accountability culture" has emerged in the developed world and that this is used as a system of governance that results in an audit society.

Policy-makers in the audit society face the challenge of giving teeth to accountability-based governance. Linking policy to stated expected outcomes is one way of doing this. To be accountable is to demonstrate that certain outcomes have been achieved. The question of evidence then arises: what evidence will show that outcomes have been achieved or improved? Answers to this question are based on a number of assumptions. One is that numerical counts provide transparent, fair and objective information about outcomes. Another is that scientific evidence will provide the information from which improvements can be made. A third assumption is that evidence must be practical, informing both policy-making and practice. Experimental research or syntheses of such research are regarded as the best evidence suited for this purpose. Gorrard \& Cook (2007) describe a variety of quantitative scientific research methods such as randomized experiments, regression-discontinuity studies and instrumental variable approaches that will provide rigorous evidence of what works. Given these answers, it is not surprising that the politics of evidence (Cheek, 2007) resulted in quantitative scientific methods gaining ascendancy, with governments mandating, favouring and funding such research and its cheaper cousin, the systematic synthesis. As a result, extensive international 
communities of scholars, such as the Campbell Collaboration, have been established to produce syntheses of educational research aimed at policy-makers. The United Kingdom and New Zealand have also established formalized programmes to conduct such reviews (Zepke \& Leach, 2006).

\section{Is the Tilt Towards Quantitative Scientific Research Justified?}

Questions of justification are complex and call on judgements that are rooted in values and assumptions. Mine are located in the interpretive domain and tend to favour mixed methods approaches to research. Although I have used quantitative approaches, I have done so tentatively and feel much more comfortable in the qualitative paradigm. The judgements made in answering the question above will therefore be influenced by these values. I will explore the question whether the tilt to the quantitative paradigm is justified by considering its strengths and limitations for the purposes of identifying what works.

\section{Strengths}

With slight variations, the arguments supporting quantitative evidence contend that, in an age where the stakes associated with being accountable are very high, research that can identify causal, empirically valid relationships between actions and outcomes must be considered as the gold standard in supporting policy (Feuer, 2006). The question "what works?" is a causal question and can only be addressed validly and safely using empirical methods (Gorard \& Cook, 2007). While conceding that such research is technically complex and relies on such things as correct sampling, absence of attrition from the sample and contamination across samples as well as sound statistical assumptions, Gorard and Cook argue that such research is necessary to identify even small effect sizes and that it would be impossible "to identify the unique causal role of any one educational practice, or set of practices, unless these practices have first been isolated and then systematically varied" (2007, p. 311). Feuer (2006) further argues that research often raises diverse and competing claims of what works. Policy-makers require rigorous ways to distinguish between such claims. Because quantitative scientific research enables even small effects on variables to be detected, such research is well placed to disentangle competing claims. Finally, a key assumption of champions of quantitative scientific research is that its results can be generalized and thus form a firm foundation for policy-making (Gorrard \& Cook, 2007).
Advocates of quantitative scientific research recognize that experiments and similar scientific methods are complex and expensive as they use intricate designs and procedures. Their results may even be disappointing, as they can be quite narrow and even provide uninformative answers (Coe, 1999; Feuer, 2006). To overcome these potential drawbacks, synthesizing the results of numerous quantitative scientific studies has found increasing favour. Meta analyses, systematic syntheses and in New Zealand, Best Evidence Synthesis Iterations attempt to do the same things as their empirical cousins. They combine the results of numerous empirical studies; give estimates of effect sizes based on "averages" of available evidence. They can also identify the factors on which the effect depends. Coe (1999) argues that this ability to combine results from separate experiments is powerful. They strengthen the generalisability of individual studies and enable the results of even small studies to provide highly useful information to policy-makers. The approaches to meta analyses and systematic syntheses favoured in the USA and UKemphasise estimating effect sizes from quantitative scientific studies such as experiments. This gives them the ability to identify empirically valid relationships between actions and outcomes, relationships that are generalisable and universal (Luke \& Hogan in Alton-Lee, 2006). The Iterative Best Evidence approach being developed in New Zealand differs in that it considers all evidence regardless of research paradigm and attempts to address its findings only to specific contexts (Alton-Lee, 2006).

\section{Limitations}

Political, ethical and technical considerations weigh against quantitative scientific research being considered the gold standard in policy-based educational research. The paper will first address political/ethical limitations before discussing technical ones.

\section{Political and ethical concerns}

Current accountability regimes underpinning evidence-based policy encourage performance management of outcomes at the expense of professional responsibility. As Biesta (2004, p. 250) observes:"against this background I am inclined to conclude that the culture of accountability ultimately makes relationships of responsibility impossible." Proponents of evidence-based policy seem to ignore the importance of the neo-liberal origins of the accountability culture. What matters is what works. As a result they minimize the effect of control that is imposed by narrow interpretations of scientific evidence. Lather (2004) accuses 
governments adopting evidence-based policies based on experimental science of creating a technology of control in their attempts to define and determine proper scientific method. Scientific research conducted in a qualitative paradigm seems to count for little. Davies $(2005$, p. 2) takes concerns about evidence-based policy even further. He argues that the excessive use of evidence in the public sphere leads to an antagonistic relationship with democracy as "in an evidence-obsessed world, both politicians and public are able to renounce their responsibilities to the political process."

Another restraint on democracy results from the claim that properly constructed quantitative scientific research leads to generalisations that are universally applicable. While manna from heaven for policy-makers, the virtues of generalisations have been disputed on both technical and political grounds (Hodkinson \& Smith, 2004; Hammersley, 2004; Adams St Pierre, 2006). Politically, faith in generalizations can lead to a politics of exclusion, a "one size fits all" a pproach to policy-making. As Hemphill (2001) points out, such an approach operates hegemonically and limits the interests of people outside the hegemony. Power emanates from a dominant centre maintained by the hegemony, which wants to maintain its dominance. Cheek (2007) pictures qualitative research as outside the hegemony, powerless, with little influence on policy and left questioning its own a pproaches. She sees it forced to work within spaces left by the hegemonic quantitative research paradigm. Acceptance of generalizations as the basis for universal policy settings can affect various populations. Lather (2004) suggests that women are one such population. Following French feminist theory she argues that the language and axioms of quantitative scientific research establish standards of truth that exclude women's ways of knowing and can only be challenged at considerable cost. Ethnic minorities are another population often excluded by the generalizing research paradigm. Maori researchers such as Smith (1999) see the hegemony of all scientific research as colonizing and not suitable for Maori.

Technical concerns

This article will now deal with three technical questions: whether generalizations about "what works" actually work to improve educational outcomes; whether rigorous scientific research as assumed in randomised experiments lessens the external validity of such research, and whether evidence provided by quantitative scientific research can address the complexity of education.
The question whether generalizations actually provide evidence of what works can be explored from at least two perspectives. One picks up on the role of contextual differences. While quantitative researchers are often willing to include variables that explain contextual differences, it is nevertheless their assumption that generalizations properly arrived at will apply to the wider population. Policies based on such generalizations will work for all. Yet this assumption is open to question. For example, in the US, UK and New Zealand, policies have been introduced to ensure that institutions are accountable for achieving set retention rates for their students. However, various researchers have suggested that such generalized expectations are not useful. Zepke, Leach and Prebble (2005) suggest that an institutional case study approach may provide better evidence for improving student outcomes than a randomised experimental study. Their survey results support this contention, as on a number of the quality indicators identified, different institutions showed different results. Moreover, they found that the most important factor in students' decisions to withdraw was frequently non-institutional - "there was too much going on in my life." Their findings are supported by Braxton and Lien (2000) in the United States and McInnis et al. (2000) in Australia, who found that individual institutions could face quite unique retention challenges; challenges that are obscured in generalizing studies. Sanderson (2003), a cautious supporter of evidence-based policy, fears that generalized evidence "will continue to provide limited purchase on causal mechanisms and present serious problems of external validity" (p. 342). It will fall short of expectations.

Another perspective on the usefulness of generalizations about what works is to ask whether governments take notice if they carry disagreeable messages. An admittedly limited sample of evidence suggests that they may not. This suggests that the idea behind evidence-based policy making is problematic. For example, in the United States, Linn (2005) using a statistical modelling technique, found that valid and reliable inferences of whether measurable outcomes for reading and mathematics were achievable could not be made from the evidence base available. Yet, such evidence continued to be used to assess institutional performance. Also using statistical modelling, Carnoy and Loeb (2004) studied the likely effects of policies on a variety of measures including retention and progression. They found no significant evidence that American states with strong policy regimes about the measures studied had better outcomes in retention and 
progression than states that did not. Policies in these states did not change. Moreover, generalizations from quantitative scientific research do not always provide uncomplicated policy information. In the United Kingdom, Boaz and Pawson (2005) examined five research syntheses on the outcomes of mentoring for at-risk youth to determine how suitable findings would be as evidence for policy-makers. Their conclusions are cause for some pessimism. They found

... that many different viewpoints flow from the reviews. Indeed there is a whole range of incompatibilities and, at their heart, some seemingly contradictory advice on whether mentoring can be recommended for at-risk youth. (p. 176)

This article will now consider questions about whether findings from quantitative scientific research can both be internally and externally valid. Internal validity refers to the extent inferences about causal relationships may be claimed to be true. External validity is the extent to which the inferences are generalisable (Trochim, 2006). Champions of quantitative scientific research claim that their research enables inferences to be made about cause and effect in their sample populations and this can be generalized to a wider population; that is, they aim for both internal and external validity. But in most research, including quantitative scientific research, there is a trade-off between internal and external validity. In a sweeping critique of experimental research, Howe (2004) argues that the more researchers restrict and refine sampling in order to achieve internal validity, the less representative of the general population the sample will be. External validity will diminish. This creates tensions for quantitative researchers who want both to establish causal relationships and generalize their findings. Howe suggests that to show what works in education, external validity should take the more prominent part. "Ironically, despite their emphasis on 'what works' this is not the ordering that experimentalists embrace" (p. 45). They are more concerned with analysing the effects of very few and well defined subjects and variables. Howe concludes that this priority selection ensures that the rigorous methodology wags the "what works" dog and

encourages educational researchers to focus on easy-to-manipulate,

simplistic interventions and to avoid questions ... that for one reason

or another, are not suited to being investigated." (p. 45)

Howe sets his sights primarily on randomised experiments. This is a narrow focus and his conclusions won't apply to all quantitative scientific research. Nevertheless, his attack does raise scepticism about whether the current dominance of quantitative research is justifiable.

In highlighting the potential for simplistic and reductionist findings from quantitative scientific research, Howe (2004) also raises the question whether it is suited to investigate the nuanced complexities of education. Lather $(2004$, p. 765$)$ does not think so. She characterises the current emphasis on science-based research as "militantly empiricist" with its claims that evidence must produce findings that are verifiable, definitive, cumulative, generalisable and immediately applicable to the policy arena. She argues that education is not so simple. Sanderson (2003) argues that this kind of evidence is indicative of an instrumental rationality, a narrow and limiting concept of both science and education. In pursuing only "what works", policy researchers are liable to leave to others the more complex tasks such as conceptualising ideas and issues, opening up the range of policy options available and challenging taken-for-granted assumptions about appropriate methods. Reductionism also poses another danger. Where scientific research offers reductionist solutions, it can be used to mislead and, according to Warren (2007), legitimise the reproduction of social advantage and disadvantage. He shows how evidence can be reported in misleading ways. He uses official reports to illustrate the point. Whereas an official report to inform policy showed that Black Caribbean students in the UK were not under-represented in higher-level mathematics examinations, its methodology failed to uncover that these students were not entered in the highest possible levels of the examinations. It seems that research will only provide evidence about education when it develops a less reductionist, more inclusive aspect. This includes the acceptance that scientific research is subjective and interpretable, always subject to debate and re-interpretation - a field of strategic possibilities (Foucault, in Lather, 2004, p. 765).

\section{What is the Future of Evidence-based Policy in Education?}

This weighing of the strengths and limitations of evidence-based policy suggests that the tilt towards quantitative scientific research can't be justified. That is not to say that quantitative scientific research lacks strengths. Its ability to establish cause and effect relationships, to identify even small effect sizes, to generalize its findings to wider populations and its ability to use systematic syntheses to bring together findings from a range of studies make quantitative scientific research a 
powerful tool in any quest to show what works. Yet, this article has also shown up some limitations of quantitative scientific research. Its hegemony inhibits recognition of other ways of knowing and researching; abilities to generalize are not always useful in understanding what works in specific contexts; external validity can be compromised by paying too much attention to constructing internally valid samples able to identify effects on a few and very precise variables; defensible answers to questions can be simplistic and reductionist, enabling evidence to mislead. In short, the domination of quantitative scientific research seems more due to political considerations than methodological virtues.

So what is the future of evidence-based educational policy research? A clear assumption of mine is that policy informed by evidence is preferable to policy that is not. So there must be a future for evidence-based policy. But on the basis of this inquiry, evidence cannot be gleaned only from quantitative scientific studies. There must be a role for qualitative methodologies. This is not a startling conclusion. Gorard and Cook (2007), two committed quantitative researchers, have already advocated the desirability of a mixed-methods approach. To them it is not an issue of what research method should have pre-eminence or what research approach is best, but what methods are best for the purposes set. Alton-Lee $(2004,2006)$, in theorizing the best evidence iteration approach in New Zealand, echoes these sentiments but has also emphasised the importance of context and using both quantitative and qualitative research to illuminate what works.

If, in the future, evidence-based policy research in education fixes on mixed-methods approaches, does quantitative scientific or qualitative scientific research have the starring role? Quantitative researchers seem to think their methodologies will. Howe (2004) suggests that they give primacy to a "mixed-method experimentalism". Certainly both Gorard and Cook (2007) and Alton-Lee (2004) seem to visualize qualitative research methods in supporting roles. Gorard and Cook assign the most important and difficult research to randomized control experiments. Alton-Lee's jigsaw methodology advocates primarily the use of experimental studies for their explanatory coherence and power. She allows for other research such as descriptive research "if careful triangulation with other outcomes-linked studies provides confidence that the evidence adds to our understanding" (Alton-Lee, 2004, p. 2). By reframing "mixed method research experimentalism" as "mixed method interpretivism", Howe (2004) reverses the positions of quantitative and qualitative research, assigning to qualitative research the lead role. While this is satisfying to qualitative researchers on a political level, a mere reversal of privilege does nothing to resolve epistemological or research design issues. Mutch (2007) argues that mixed methods must be justified according to sound theoretical considerations. This implies that neither "mixed method experimentalism" nor "mixed method interpretivism" can expect automatic primacy. This can only be decided on the basis of sound conceptual considerations. Mutch (2007) advances five guidelines to determine whether qualitative or quantitative methods will lead mixed methods research: contextual sensitivity, creativity, conceptual awareness, coherence and critical awareness. Using such guidelines denies automatic primacy to both qualitative and quantitative methods. Research designs can be based on what works in a particular situation and not on a preconceived "gold standard".

\section{References}

Adams St. Pierre, E. (2006). Scientifically based research in education: Epistemology and ethics. Adult Education Quarterly, 56(4), 239-266.

Alton-Lee, A. (2004). Improving educational policy and practice through an iterative best evidence synthesis programme. OECD-US Seminar on Evidence-based Policy Research, Washington, DC.

Alton-Lee, A. (2006, March). Iterative best evidence synthesis: Strengthening research, policy and practice links to improve outcomes. Paper presented at the 4th Annual Policy Conference: Policy Evolution. Accessed on October 12, 2007, from

$<$ www.educationcounts.govt.nz/ data/assets/pdf file/0004/6646/ ibes-4th-annual-policy-conference $>$.

Ball, S. (1998). Big policies/small world: An introduction to international perspectives in education policy. Comparative Education, 34(2), 119130.

Barone, T. (2007). A return to the gold standard? Questioning the future of narrative construction as educational research. Qualitative Inquiry, 13(4), 454-470.

Braxton, J., \& Lien, L. (2000). The viability of academic integration as a central construct in Tinto's interactionalist theory of college student departure. In J. Braxton (Ed.), Reworking the student departure puzzle (pp. 11-28). Nashville: Vanderbilt University Press. 
Biesta, G. (2004). Education, accountability, and the ethical demand: Can the democratic potential of accountability be regained? Educational Theory, 54(3), 233-250.

Boaz, A., \& Pawson, R. (2005). The perilous journey from evidence to policy: Five journeys compared. Journal of Social Policy, 34(2), 175-194.

Carnoy, M., \& Loeb, S. (2004). Does external accountability affect student outcomes? A cross-state analysis. In S. Fuhrman \& R. Elmore (Eds.), Redesigning accountability systems for education (pp. 189-219). New York: Teachers College Press.

Charlton, B. (2002). Audit, accountability, quality and all that: The growth of managerial technologies in UK universities. In S. Prickett \& P. Erskine-Hill (Eds.), Education! Education! Education! Managerial ethics and the law of unintended consequences (pp. 18-28). Exeter: Imprint Academic.

Cheek, J. (2007). Qualitative inquiry, ethics, and politics of evidence: Working within these spaces rather than being worked over by them. Qualitative Inquiry, 13(8), 1051-1059.

Codd, J. (2002). The Third Way for tertiary education policy: TEAC and beyond. New Zealand Annual Review of Education, 11, 31-57.

Coe, R. (1999). A manifesto for evidence-based education. The Curriculum, Evaluation and Management Centre. Retrieved on December 19, 2007 from <www.cemcentre.org/renderpage.asp?linkID $=30317000>$.

Daun, H. (Ed.). (2002). Educational restructuring in the context of globalization and national policy. New York: Routledge Falmer.

Davies, W. (2005). Evidence-based policy and democracy. Open Democracy: Free thinking for the world. Retrieved on December 12, 2005, from <www.openDemocracy.net $>$

Davies, H., \& Nutley, S. (2001, July). Evidence-based policy and practice: Moving from rhetoric to reality. The International, Interdisciplinary Evidence-based Policies and Indicator Systems Conference (pp. 8695). Durham: CEM Centre, University of Durham.

Edwards, R., \& Usher, R. (1998). Moving experiences: Globalization, pedagogy and experiential learning. Studies in Continuing Education, $20(2), 159-174$.
Feuer, M. (2006). Response to Bettie St. Pierre's "Scientifically based research in education: Epistemology and ethics". Adult Education Quarterly, 56(4), 267-272.

Feuer, M., Towne, L., \& Shavelson, R. (2002). Scientific culture and educational research. Educational Researcher, 31(8), 4-14.

Gorard, S., \& Cook, T. (2007). Where does good evidence come from? International Journal of Research and Method in Education, 30(3), 307-323.

Hemphill, D. (2001). Incorporating postmodernist perspectives into adult education. In V. Sheared \& P. Sisel (Eds.), Making space: Merging theory and practice in adult education (pp. 15-28). Westport, CT: Bergin and Garvey.

Hammersley, M. (2004). Some questions about evidence-based practice in education. In G. Thomas \& R. Pring (Eds.), Evidence-based practice in education (pp. 133-149). Maidenhead: Open University Press.

Hodkinson, P., \& Smith, J. (2004). The relationship between research, policy and practice. In G. Thomas \& R. Pring (Eds.), Evidence-based practice in education (pp. 150-165). Maidenhead: Open University Press.

Howe, K. (2004). A critique of experimentalism. Qualitative Inquiry, 10(1), 42-61.

Lather, P. (2004). Scientific research in education: A critical perspective. British Educational Research Journal, 30(6), 759-772.

Linn, R. (2005). Scientific evidence and inference in educational policy and practice: Implications for evaluating adequate yearly progress. In C. Dwyer (Ed.), Measurement and research in the accountability era (pp. 21-30). Mahwah, NJ: Lawrence Erlbaum Associates.

McInnis, C., Hartley, R., Polesel, J., \& Teese, R. (2000). Non-completion in vocational education and training and higher education: A literature review. Canberra: Department of Employment, Education, Training and Youth Affairs (DEETYA).

Ministry of Education. (2004). Statement of Intent 2004-2009. Retrieved on January 10, 2006, from <www.minedu.govt.nz/web/downloadable/ d19644_v1/soi - 2004-2009.pdf >.

Ministry of Education. (2005). Statement of Intent 2005-2010. Retrieved on January 10, 2006, from <www.minedu.govt.nz/web/downloadable/ dl10361_vi/statement-of-intent-2005 - 2010.pdf $>$. 
Mulderrig, J. (2003). Consuming education: A critical discourse analysis of social actors in New Labour's education policy. Journal for Critical Education Policy Studies [Online], 1(1). Retrieved on December 28, 2005, from <www.jceps.com/index.php?pageID=article\&articleID =2>.

Mutch, C. (2007). Mixed method research: Methodological eclecticism or muddled thinking? Paper delivered at the annual conference of the New Zealand Association for Research in Education (NZARE), Christchurch, December.

Olssen, M. (2001). The neo-liberal appropriation of tertiary education policy in New Zealand: Accountability, research and academic freedom. New Zealand Association for Research in Education "State-of-the-Art" Monograph No 8. Palmerston North: NZARE.

Olson, D. (2004). The triumph of hope over experience in the search of "what works": A response to Slavin. Educational Researcher, 33(1) 24-26.

Sanderson, I. (2003). Is it "what works" that matters? Evaluation and evidence-based policy-making. Research Papers in Education, 18(4), 331-345.

Smith, L. (1999). Decolonizing methodologies: Research and indigenous people. Dunedin: University of Otago Press.

Taylor, D. (2005). Governing through evidence: Participation and power in policy evaluation. Journal of Social Policy, 34(4), 601-618.

Trochim, W. (2006). The Research Methods Knowledge Base (2nd ed.). Retrieved on January 8, 2008, from <www.socialresearchmethods.net/kb/>.

Warren, S. (2007). Migration, race and education: Evidence-based policy or institutional racism? Race Ethnicity and Education, 10(4), 367-385.

Zepke, N., Leach, L., \& Prebble, T. (2005). Now you have got them how do you keep them? Factors that influence student departure and persistence. New Zealand Journal of Educational Studies, 40(1\&2) $181-200$.

Zepke, N., Leach, L., \& Prebble, T. (2006). Being learner-centred: One way to improve retention? Studies in Higher Education, 31(5), 587-600.

\section{The author}

Nick Zepke is an Associate Professor in the College of Education at Massey University with research interests that focus on futures and policy studies, student engagement, retention and outcomes. 